\title{
US posts sensitive climate report for public comment
}

Climate experts have expressed surprise and concern about a US government decision to release a politically sensitive report when it is still in draft form.

Access to the first section of the Intergovernmental Panel on Climate Change (IPCC) Fourth Assessment Report, due for publication in 2007, has been open for around a month. IPCC reports are designed to inform political negotiations on climate change, and key statements in the assessments can influence debate for years after publication. The first section, called Working Group I (WGI), offers an overview of the science of climate change and predictions about the possible course of global warming.

The US government says its move will allow the broadest range of experts to comment, and will avoid accusations that any groups have been denied access. But the decision effectively to publish the report worries some researchers, who say it could undermine what has previously been a confidential review process.

${ }^{\alpha}$ If the US government is "If the US government going to allow lobby groups, or allows lobby groups persons associated with them, input into the government review, there is a serious chance that the whole thing could get hijacked," says one US government scientist involved in the process.

The WGI chapters of the assessment have completed one round of scientific review and are now with national governments. Most countries have solicited comments from a small number of experts, but the US Climate Change Science Program, which coordinates US climate research efforts on behalf of the government, posted the draft online on 7 April, together with a notification in the Federal Register. The climate science programme also sent out an e-mail to "thousands" of scientists, environmental groups and industry lobbyists, inviting them to comment. The website and report itself note that the contents should not be distributed or quoted, despite the fact that they can be accessed by asking for a password, which is provided automatically.

"I was quite surprised," says a senior IPCC scientist, who spoke on condition of anonymity. "I never thought they would do something like this." Rajendra Pachauri, the panel's chairman, did not learn of the decision until after the report was posted online. He says that it is not in keeping with past practice, but adds that he could not interfere with how governments choose to collect comments. Lead authors on the WGI report dedined to comment.

Roger Pielke Jr, a climate-policy expert at the University of Colorado, Boulder, suggests that the move could be seen as a deliberate strategy to defuse the newsworthiness of the final report. "If the report is already out there in circulation, then the 'news' value is likely to be much diminished when the official report is finally released," he says. The current US administration has been critical of the workings of the IPCC and its conclusions.

\section{Up for debate}

But Pielke adds that this isn't the only interpretation: "Less cynically, I do think that scientific assessments should be done much more in a continuous mode than the discrete approach favoured by the IPCC. So if this is a step in that direction, there could be some value." Other climate experts contacted by Nature also welcomed the open approach, while questioning the motivation.

Governments have until 2 June to send comments to the IPCC. Those familiar with the process say that the chapters are unlikely to change substantially, but that the technical and policy-maker summaries will attract many comments. The current draft, which represents the message that the scientific authors want to present to policymakers, contains few statements that will surprise climate researchers, but its tone is much more confident than that of its predecessor, published in 2001. And that, say researchers, will make it harder for sceptical politicians and lobbyists to attack climate predictions.

${ }^{\alpha}$ People won't be punching holes in the science," says Jay Gulledge, a senior research fellow at the Pew Center on Global Climate Change in Arlington, Virginia. Emily Shuckburgh, a climate researcher at the University of Cambridge, UK, agrees: 'If you're a sceptic, it's difficult to see where to attack on the modelling side."

One critical number in previous reports has been the sensitivity of the climate to increases in greenhouse-gas levels. In 2001, scientists esti-

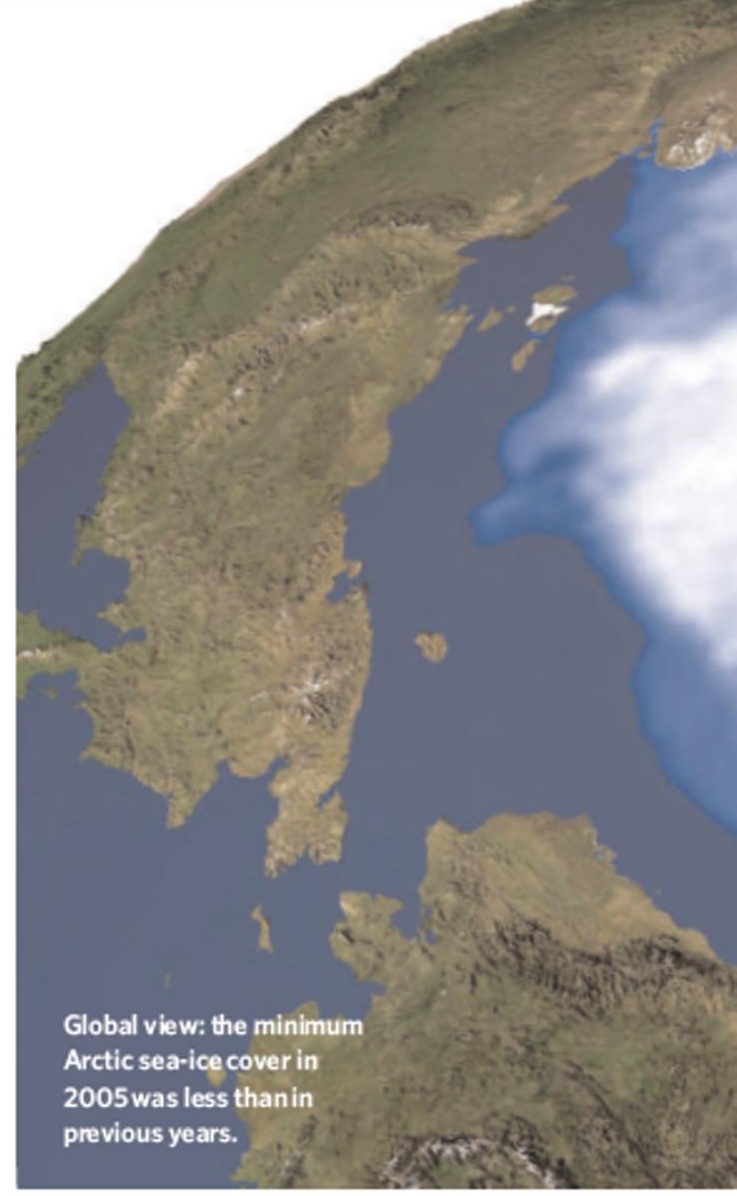

mated that a doubling of carbon dioxide levels would cause an increase of $1.5-4.5^{\circ} \mathrm{C}$, but acknowledged that this range was little more than a best guess. The draft 2007 WGI report describes how new models and data sets allow the range to be properly quantified. It estimates the effect of doubling carbon dioxide as a rise of $2.0-4.5^{\circ} \mathrm{C}$ and, for the first time, suggests a single most likely figure: $3^{\circ} \mathrm{C}$. This estimate is already widely accepted by climate scientists.

\section{Commitment to change}

Another set of predictions that have become much more robust are those about 'commitment' - the ongoing climatic changes that would be expected even if greenhouse-gas levels could be stabilized. The existence of commitment was acknowledged in the last WGI report, but no number was given in the policymakers' summary. In contrast, the 2007 summary stresses that even if greenhouse gases level off now, warming will continue at about the current rate for several decades.

The error bars have also shrunk substantially on one of the biggest uncertainties in 2001 the role of aerosols such as soot from fires, which exert a cooling effect by reflecting sunlight. In addition, certainty over politically 


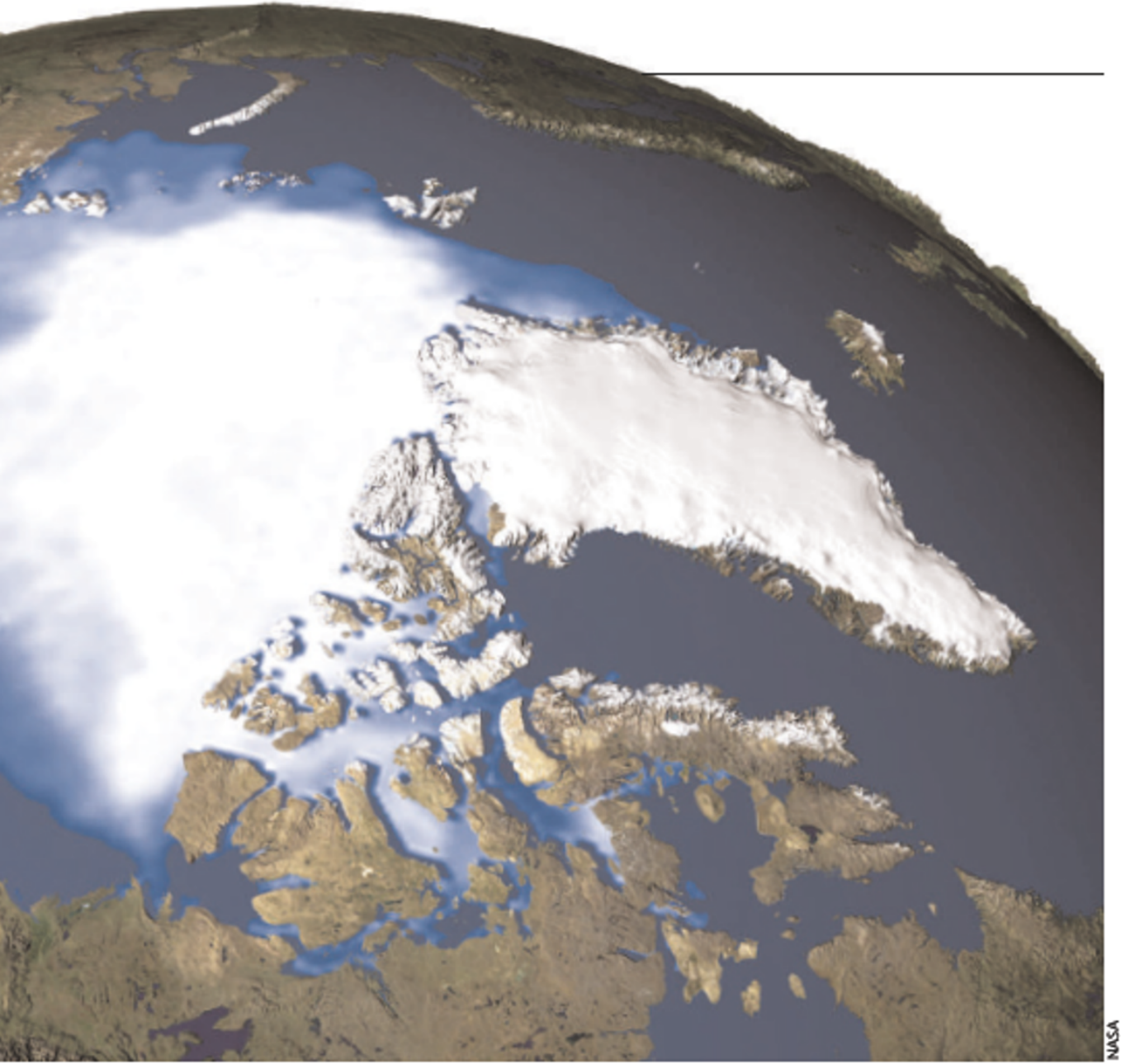

important statements about whether dimate change has already been observed has increased. Data on twentieth-century changes in precipitation and sea-level rise are now more precise, and the risk of ocean acidification is detailed for the first time. Such assertions are likely to be seized on by environmental groups if they appear in the final document.

Reports of Working Groups II and III, which cover the consequences of climate change and the attempts to tackle it, are due later in 2007. An overall policy-makers' summary covering all three components will then be produced. In previous years this has been negotiated line by line by politicians, some of whom have been
"If you're a sceptic, it's difficult to see where to attack on the modelling side." seized on by sceptics as evidence that they were right to question the graph's validity; however, there is a similar graph in the current summary, which shows a dramatic twentiethcentury rise in the degree to which greenhouse gases trap energy in the atmosphere.

If the confident tone of the draft survives, policy experts say it could have quite an impact. Kyoto Protocol negotiations have started to examine what will happen when the current agreement expires in 2012. Similar discussions are being run by the Group of Eight industrialized nations, and by the Asia-Pacific Partnership on Clean Development and Climate, which includes the United States and accused of seeking to downplay certain findings to protect national interests, such as the petroleum industry. The 2001 version took four days to finalize.

One graph in that summary, known as the 'hockey stick' and used to illustrate temperature change over the past millennium, has caused controversy for years, and is omitted in the current draft of the 2007 WGI policy-makers' summary, although an updated version is in the larger document. This is likely to be
Australia, neither of which is party to Kyoto.

"Several negotiation processes are ongoing," says Michael Grubb, a climate-policy expert at Imperial College, London, who is involved in WGII and WGIII. "That creates ripe ground for substantial political impact."

Jim Giles

Comments on the IPCC report can be submitted until

9 May. Details of how to access it can be found at

www.climatescience.gow/Library/ipce/

wg14ar-review.htm
ON THE RECORD

'Hedgehogs have been around for 20 million years - we want them around in the next century."

Ecologist Paul Bright expresses concern for Britain's disappearing hedgehogs. They will now be tracked by the internet-based 'HogWatch'.

\section{"Among the astronaut's needs are guidelines on performing prayers in space."}

A Malaysian govemment official discusses unique concerns faced by the country's first astronaut, a Muslim.

Source: Reuters

\section{SCORECARD}

\section{Space-agescavengers NASA form sa 'roadkill posse' to deter vultures} around the shuttle launch pad by removing the carrion on which they feed. The birds came under fire after one struck Discovery as it took off last year.

\section{$\triangle$ Clam confusion Pollutants are sowing a gender cris is among}

Britain's bivalves, causing as many as $60 \%$ of male clams tomake eggs.

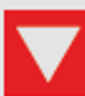
Piegobblers
Drug company Bayer,
maker of the Alka-Seltze heartburn remedy, drops its sponsorship of a worldwide speed-eating contest.

\section{NUMBER CRUNCH}

Biochemist Akira Endo has an obsession: "Ilove mushrooms and moulds." In 1973, he isolated the chemical ML-236B from a fungus it was to form the basis of the famed cholesterol-lowering drugs known as statins. The work wins him this year's Japan Prize for new therapies.

6,000 mushrooms and moulds were studied by Endo before he discovered ML-236B.

Nothing was earned by Endo for statins, because his patent expired before the drugs took off.

Y50 million or Us\$440,000 was awarded to Endo as a Japan Prize winner. 